\title{
Fermented Milk and Protection from Cardiovascular Disease
}

\author{
Magdy Mohamed Ismail* \\ Dairy Technology Department, Animal Production Research Institute, Egypt
}

Submission: September 10, 2017; Published: September 20, 2017

*Corresponding author: Magdy Mohamed Ismail, Dairy Technology Department, Animal Production Research Institute, Agricultural Research Center, Egypt; Email: magdy250@yahoo.com

\section{Editorial}

Milk is a fluid lacteal secretion obtained by the female of all mammals. Milk has an important function because it is a source of the essential nutrients for the proper development and maintenance of the human body. It must supply amino acids, vitamins, and minerals. It is very beneficial to balance human diet. Because milk has good quality protein such as caseins and serum proteins, it also has good amount of calcium and vitamins, specially vitamin A, B and C, riboflavin, niacin and folic acid.

Hence, milk is an ideal nutrient for both infants and adults [1]. Moreover, milk contains bio-protective molecules which are afford health security to humans including antimicrobial substances such as immunoglobulin, lactoperoxidase and lactotransferrin and it also contains enzymes and enzyme inhibitors, vitamin-binding carrier proteins [2]. Further it contains trace elements such as nickel, selenium, zinc and iron.

On the other side, fermentation has being used in foods for thousands of years according to archaeological evidence. From time to time fermentation started to use for longer shelf life, and higher nutritional values. Today this technique is commonly using in vegetables, fruits, cereals, meat, milk and fish and the fermented products are consumed around the world [3].

Fermented dairy foods have constituted a vital part of human diet in many regions of the world since times immemorial. They have been consumed ever since the domestication of animals. Evidence for the use of fermented milks comes from archeological findings associated with the Sumerians and Babylonians of Mesopotamia, the Pharoses of northeast Africa and the Indo-Aryans of the Indian subcontinent. It was reported that consuming fermented dairy products caused to longevity $[4,5]$.

Fermented milk products not only are consumed for their benefits but also for refreshing effects. Their popularity is said to be attributed to the effective use of consumer-driven flavors and milder cultures. These products already have a positive health image $[6,7]$, which can be further enhanced by the addition of probiotic bacteria with therapeutic properties.

Cardiovascular disease (CVD) is the leading cause of death globally, with more people dying annually from CVD than from any other cause [8]. Coronary heart disease (CHD) is the most common type of heart disease. CVD is an umbrella term that includes CHD and vascular diseases of the brain and blood vessels [9]. The etiology of CVD includes atherosclerosis, an inflammatory process that leads to hardening and narrowing of blood vessels, plaque build-up in vessel walls, and eventually plaque rupture, heart attack, or stroke [9]. Modifiable risk factors that play a role in the development of atherosclerosis include physical inactivity, overweight, and obesity [9].

The consumption of dairy, including milk, cheese and yogurt, has been associated with better quality of diet and reduced risk of cardiovascular disease. Rice [10] reviewed eighteen observational studies. The results indicate that total dairy intake does not contribute to cardiovascular disease incidence or death. Based on available data, it appears that milk, cheese, and yogurt are inversely associated with cardiovascular disease risk.

There are several studies indicating that milk and milk products may not affect adversely blood lipids as would be predicted from its fat content and fat composition. There are even factors in milk and milk products which may actively protect from this condition by improving several risk factors. Calcium, bioactive peptides and as yet unidentified components in whole milk may protect from hypertension, and folic acid, vitamin B6 (pyridoxine) and B12 (cyanocobalamin) or other unidentified components of skim milk may contribute to low homocysteine levels. Conjugated linoleic acid may have hypolipidaemic and anti-oxidative and thus antiatherosclerotic properties. Epidemiological studies suggest 
that milk and milk products fit well into a healthy eating pattern emphasizing cereals and vegetables [11].

Tholstrup [12] wrote that some specific bacterial strains may have cholesterol-reducing properties, while some fermented products (especially those produced using Lactobacillus helveticus) can decrease hypertension. In addition, a recent study reported a statistically significant inverse relationship between fermented milk consumption and CVD, with the highest level of intake (238g/day for women, $273 \mathrm{~g} /$ day for men) being associated with 15 percent decreased incidence of CVD compared with the lowest level of intake (40g/day for women and 43g/day for men) [13]. Goldbohm et al. [14] also reported that consumption of fermented full-fat milk was inversely associated with all-cause mortality for men and women and non-significantly with stroke mortality in both men and women. Dalmeijer et al. [15] reported a borderline inverse association between intake of fermented dairy products and risk of stroke $(\mathrm{HR}=0.92$; 95 percent $\mathrm{CI}$ : 0.83-1.01), supporting this result.

Yogurt and fermented milk may protect against heart disease [16,17]. An observational study among more than 26,000 middle-aged Swedish adults showed that fermented dairy products such as yogurt significantly reduced risk for CVD in those who consumed the highest intake vs. the lowest intake [16]. The potential cardio protective effect (i.e., lower risk of developing a first heart attack) of consuming cheese and fermented milk products was supported by a large prospective, case-control study that used objective biomarkers of milk fat intake (i.e., serum levels of ruminant specific fatty acids, pentadecanoic acid [15:0] and heptadecanoic acid [17:0]) [17].

Observational studies indicate that the consumption of milk or dairy products is inversely related to incidence of CVD. The consumption of dairy products has been suggested to ameliorate characteristics of the metabolic syndrome, which encompasses a cluster of risk factors including dyslipidemia, insulin resistance, increased blood pressure, and abdominal obesity, which together markedly increase the risk of diabetes and CVD. Dairy products, such as cheese, do not exert the negative effects on blood lipids as predicted solely by the content of saturated fat. Calcium and other bioactive components may modify the effects on LDL cholesterol and triglycerides. Apart from supplying valuable dairy nutrients, yogurt may also exert beneficial probiotic effects. The consumption of yogurt, and other dairy products, in observational studies is associated with a reduced risk of weight gain and obesity as well as of CVD, and these findings are, in part, supported by randomized trials [18].

The mechanisms by which dairy foods, regardless of fat content, may reduce the risk of CVD have not been fully elucidated. A recent review of dairy components and risk for cardio metabolic syndrome explores some of the proposed mechanisms by which dairy may beneficially affect CVD risk [19]. In brief, the milk fat component of dairy contains over 400 unique fatty acids, many of which are not found in other foods [20]. Milk fat contains saturated, monounsaturated, and polyunsaturated fatty acids of varying chain lengths and configurations. The study of milk fatty acid chemistry is complex, and some studies have suggested that bioactive fatty acids in milk fat are responsible for anti-inflammatory and improved metabolic effects $[21,22]$. In addition, the minerals contained in dairy foods, such as calcium, magnesium, phosphorus, and potassium, have been implicated in the management of elevated blood pressure and cardio metabolic syndrome [19]. Furthermore, calcium from dairy has been implicated in fecal fat excretion and the maintenance of healthy blood lipids [23]. Dairy foods are complex, however, and more recent evidence indicates that the dairy food matrix may be just as important as its individual components [24]. There are likely multiple mechanisms by which dairy consumption may help reduce CVD risk.

\section{References}

1. Yetisemeyen A, Sezgin E, Atamer M, Koçak C, Gürsel, et al. (2007) SütTeknolojisi Ankara Üniversitesi Ziraat Fakültesi Süt Teknolojisi Bölümü Ankara. Yayın no: 1560.

2. Fox PF, Guinee TP, Cogan TM, McSweeney PLH (2000) Fundamentals of Cheese Science. Gaithersburg, Maryland: Aspen Publishers.

3. Farnworth E R (2005) Kefir - a Complex Probiotic. Food Science and Technology Bulletin: Functional Foods 2(1): 1-17.

4. Tamime AY, Robinson RK (2007) Yogurt Science and Technology. ( $3^{\text {rd }}$ edn), Wood head Publishing Limited, Cambridge, England/CRC Press, Boca Raton, FL.

5. Chandan RC, Nauth KR (2012) Yogurt. Handbook of Animal-based Fermented Food and Beverage Technology ( $2^{\text {nd }}$ edn) (Chapter 12). In: Hui Y H \& Chandan RC. CRC Press, Boca Raton, FL, USA, pp. 213-233.

6. Jelen P, Gallmann P, Coolbear T (2003) Current and future applications of fermentation technology in the dairy industry. IDF Seminar on Aroma and Texture of Fermented Milk, p. 10.

7. Valli C, Traill W B (2005) Culture and food: A model of yoghurt consumption in the EU. Food Qual. Pref. 16: 291-304.

8. World Health Organization (2011) Global status report on noncommunicable diseases. Geneva.

9. Mendis S, Puska P, Norrving B (2011) World Health Organization Global atlas on cardiovascular disease prevention and control. Geneva.

10. Rice B H (2014) Dairy and Cardiovascular Disease: A Review of Recent Observational Research. Curr Nutr Rep 3(2): 130-138.

11. Pfeuffer M, Schrezenmeir J (2000) Bioactive substances in milk with properties decreasing risk of cardiovascular diseases. British Journal of Nutrition 84(Suppl 1): 155-159.

12. Tholstrup T (2006) Dairy products and cardiovascular disease. Curr. Opin. Lipidol 17(1): 1-10.

13. Sonestedt E, Wirfält E, Wallström P, Gullberg B, Orho-Melander M, et al. (2011) Dairy products and its association with incidence of cardiovascular disease: the Malmö diet and cancer cohort. Eur. J. Epidemiol 26(8): 609-618. 
14. Goldbohm RA, Chorus AM, Galindo Garre F, Schouten LJ, van den Brandt PA (2011) Dairy consumption and 10-y total and cardiovascular mortality: a prospective cohort study in the Netherlands. Am J Clin Nutr 93(3): 615-627.

15. Dalmeijer GW, Struijk EA, van der Schouw YT, Soedamah-Muthu SS, Verschuren WM, et al. (2012) Dairy intake and coronary heart disease or stroke - a population-based cohort study. Int J Cardiol 167(3): 925929.

16. Sonestedt E, Wirfalt E, Wallstrom P, Gullberg B, Orho-Melander M, et al. (2011) Dairy products and its association with incidence of cardiovascular disease: the Malmo diet and cancer cohort. Eur J Epidemiol 26(8): 609-618.

17. Warensjo E, Jansson J H, Cederholm T, Boman K, Eliasson M, et al (2010) Biomarkers of milk fat and the risk of myocardial infarction in men and women: a prospective, matched case-control study. Am J Clin Nutr 92(1): 194-202.

18. Astrup A (2014) Yogurt and dairy product consumption to prevent cardio metabolic diseases: epidemiologic and experimental studies. Am J ClinNutr 99: 1235-1242.
19. Rice BH, Cifelli CJ, Pikosky MA, Miller GD (2011) Dairy components and risk factors for cardio metabolic syndrome: recent evidence and opportunities for future research. Adv Nutr 2: 396-407.

20. Jensen R G (2002) The composition of bovine milk lipids: January 1995 to December 2000. J Dairy Sci 85(2): 295-350.

21. Mozaffarian D, de Oliveira Otto MC, Lemaitre RN, Fretts AM, Hotamisligil G, et al. (2013) Trans-palmitoleic acid, other dairyfat biomarkers, and incident diabetes: the Multi-Ethnic Study ofAtherosclerosis (MESA). Am J Clin Nutr 97(4): 854-861.

22. Dilzer A, Park Y (2012) Implication of conjugated linoleic acid (CLA) inhuman health. Crit Rev Food Sci Nutr 52(6): 488-513.

23. Lorenzen JK, Astrup A (2011) Dairy calcium intake modifies responsiveness of fat metabolism and blood lipids to a high-fat diet. Br J Nutr 1: 1-10.

24. Astrup A, Dyerberg J, Elwood P, Hermansen K, Hu FB, et al. (2011) The role of reducing intakes of saturated fat in theprevention of cardiovascular disease: where does the evidence stand in 2010? Am J ClinNutr 93(4): 684-688.

\section{Your next submission with Juniper Publishers will reach you the below assets}

- Quality Editorial service

- Swift Peer Review

- Reprints availability

- E-prints Service

- Manuscript Podcast for convenient understanding

- Global attainment for your research

- Manuscript accessibility in different formats

( Pdf, E-pub, Full Text, Audio)

- Unceasing customer service

Track the below URL for one-step submission https://juniperpublishers.com/online-submission.php 